\title{
A retrograde tunnelling technique for regional anesthesia catheters: how to avoid the skin bridge
}

\author{
Carole Lin, MD • Travis Reece-Nguyen, MD • Ban C. H. Tsui, MD, MSc $\mathbb{B}$
}

Received: 20 September 2019/Revised: 7 October 2019/Accepted: 7 October 2019/Published online: 15 October 2019

(C) Canadian Anesthesiologists' Society 2019

\section{To the Editor,}

Tunnelling of continuous regional anesthesia catheters has been suggested to provide stability/reduce dislodgement ${ }^{1}$ and to decrease the infection risk from bacterial colonization, particularly for epidural catheters. ${ }^{2}$ Despite tunnelling typically involving relatively minimal time and additional equipment, it remains an underutilized technique and is not commonly taught in most training programs. Some tunnelling-related complications have been reported, including the catheter breaking off at the $\operatorname{skin}^{3}$ as well as difficulties extracting the catheter requiring surgical intervention. Thus, it is important to review several key steps of a successful retrograde tunnelling technique that can decrease the potential for catheter damage and minimize the skin bridge (i.e., infection risk from exposing the catheter at the original puncture site) that can occur with more conventional tunnelling methods. ${ }^{4}$ In the figure and accompanying video, the retrograde tunnelling technique is demonstrated in a porcine model.

After placing the catheter at the desired location and depth, the clinician should carefully remove the Touhy regional needle while ensuring that the catheter position remains unchanged. This is accomplished using a looping technique to stabilize the catheter while removing the

Electronic supplementary material The online version of this article (https://doi.org/10.1007/s12630-019-01505-6) contains supplementary material, which is available to authorized users.

C. Lin, MD - T. Reece-Nguyen, MD ·

B. C. H. Tsui, MD, MSc ( $\)$.

Department of Anesthesiology, Perioperative and Pain Medicine, Lucille Packard Children's Hospital, Stanford University, School of Medicine, Stanford, USA

e-mail: bantsui@stanford.edu needle with deliberate and equal motions to avoid knotting the catheter while simultaneously maintaining control of the catheter position with pressure at the skin entry site. After adequate local anesthetic infiltration, the subcutaneous tunnelling begins with insertion of the styleted Touhy needle tip while directing its bevel away from the catheter. Using a sterile syringe with its plunger removed as a needle shield, one can protect from any inadvertent skin puncture to the patient and clinician as well as providing counter-pressure to aid the tunnelled Touhy in exiting through the skin. Once the tunnelling needle exits, the stylet of the Touhy needle is removed, and a sterile well-fitted guidewire (e.g., Arrow AW-14732 with outer diameter 0.032 inches $/ 0.81 \mathrm{~mm}$, Teleflex ${ }^{\circledR}$, USA) is inserted through the $17 \mathrm{G}$ (inner diameter 0.036 inches $/ 0.91$ $\mathrm{mm}$ ) or $18 \mathrm{G}$ (inner diameter 0.032 inches $/ 0.81 \mathrm{~mm}$ ) Touhy needle. Next, the needle is withdrawn while keeping the guidewire in the subcutaneous tunnel. Using the guidewire, the Touhy needle is threaded back towards the initial insertion point (i.e., the catheter). To minimize risk of catheter damage, the clinician should turn the tunnelling needle bevel $90^{\circ}$ facing away from the catheter as the needle advances over the wire. Once again, the use of a needle shield can help avoid any inadvertent skin puncture. After removing the guidewire, the regional anesthesia catheter is fed back into the regional needle being careful not to knot the advancing catheter. Counter tension on the catheter can be applied as it passes smoothly though the regional needle, with care to avoid shearing it at the bevel. When the catheter loop has approximately 6-9 $\mathrm{cm}$ remaining, the regional needle can be removed leaving a small loop of catheter to be pulled through the skin. Before doing so, the catheter depth should be noted at the original insertion point before the loop disappears to ensure that the catheter position has not been inadvertently dislodged. 
Figure Photographs of retrograde tunnelling on a porcine model. A) Catheter in place and a Touhy needle tunnelling through the skin beginning where the catheter originally exited the skin. A counter-pressure syringe barrel is ready to be used as shield when the needle re-exits the skin. B) Wire being passed through the first tunnelling needle. C) The needle now reversed and tunnelling back over the wire towards the catheter. D) The catheter being inserted back into the tunnelling needle
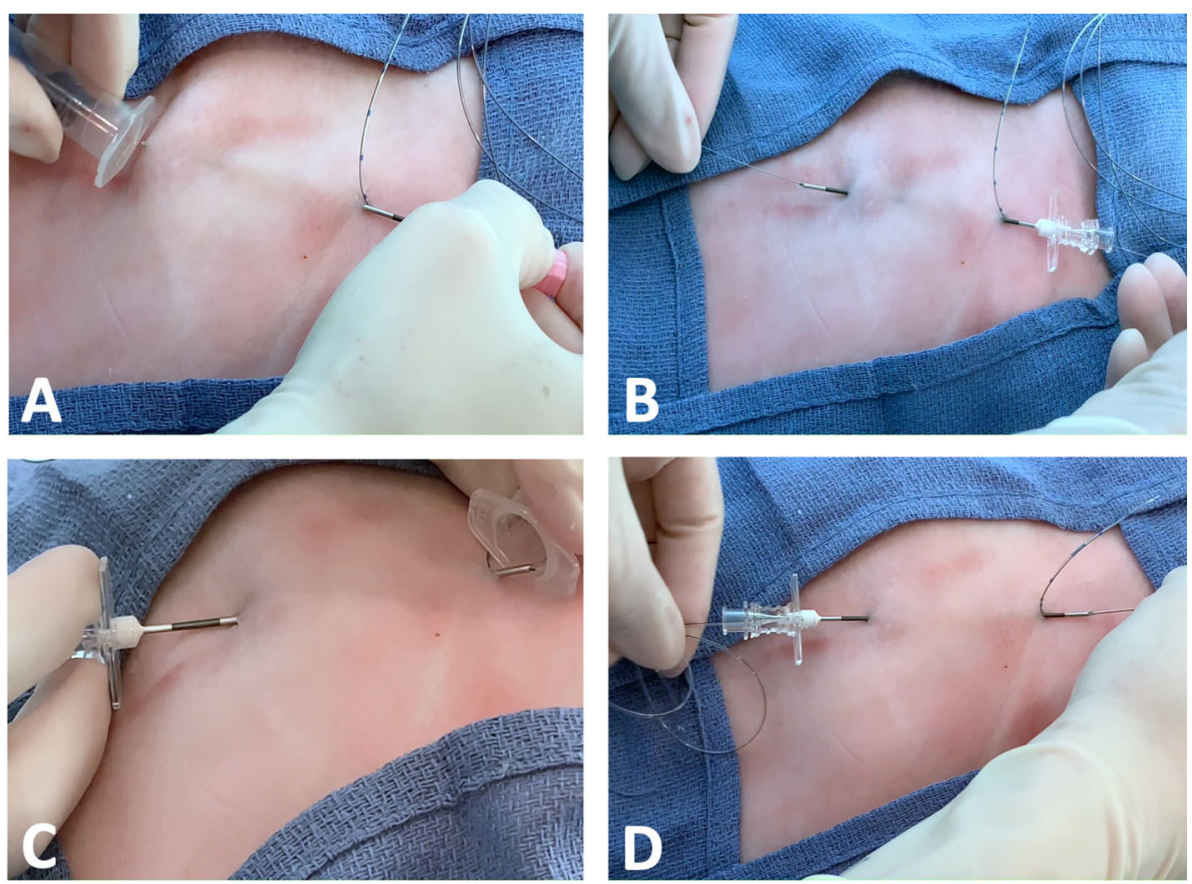

Finally, the initial and final needle insertion sites can be covered with a sterile bio-occlusive dressing.

It is important to point out that it remains controversial whether a catheter (tunnelled or not) should be placed in those who are actively septic. ${ }^{5}$ In addition, the benefits of tunnelling must be weighed against the additional bleeding risks in anticoagulated patients. Overall, we found that this retrograde technique is simple to perform and avoids creating a skin bridge, which commonly occurs when utilizing the traditional tunnelling technique.

Conflict of interest None declared.

Editorial responsibility This submission was handled by Dr. Hilary P. Grocott, Editor-in-Chief, Canadian Journal of Anesthesia. dislodgement. ScientificWorldJournal 2014; DOI: https://doi.org/ 10.1155/2014/610635.

2. Vas L, Naik V, Patil B, Sanzgiri S. Tunnelling of caudal epidural catheters in infants. Paediat Anaesth 2000; 10: 149-54.

3. Han JY, Shin I, Park M, Lee SH, Kim MG, Kim YA. Removal of a sheared radiolucent epidural catheter during subcutaneous tunneling through localization by computed tomography: a case report. International Journal of Pain 2016; 7: 13-7.

4. van de Putte $P$, van der Vorst $M$. Continuous interscalene block using a stimulating catheter: a review of the technique. Acta Anaesthesiol Belg 2005; 56: 25-30.

5. Wedel DJ, Horlocker TT. Regional anesthesia in the febrile or infected patient. Reg Anesth Pain Med 2006; 31: 324-33.

Publisher's Note Springer Nature remains neutral with regard to jurisdictional claims in published maps and institutional affiliations.

\section{References}

1. Sellmann T, Bierefischer V, Schmitz A, et al. Tunneling and suture of thoracic epidural catheters decrease the incidence of catheter 